\title{
Mapping quantitative trait loci for T lymphocyte subpopulations in peripheral blood in swine
}

\author{
Xin $\mathrm{Lu}^{1,2+}$, Jian-Feng Liư ${ }^{1 \dagger}$, Yuan-Fang Gong ${ }^{1,3}$, Zhi-Peng Wang ${ }^{1}$, Yang Liu ${ }^{1}$ and Qin Zhang ${ }^{1 *}$
}

\begin{abstract}
Background: Increased disease resistance through improved general immune capacity would be beneficial for the welfare and productivity of farm animals. T lymphocyte subpopulations in peripheral blood play an important role in immune capacity and disease resistance in animals. However, very little research to date has focused on quantitative trait loci (QTL) for T lymphocyte subpopulations in peripheral blood in swine.

Results: In the study, experimental animals consist of 446 piglets from three different breed populations. To identify QTL for T lymphocyte subpopulations in peripheral blood in swine, the proportions of CD4+, CD8+, CD4+CD8+, CD4+CD8-, CD4-CD8+, and CD4-CD8- T cells and the ratio of CD4+:CD8+ T cells were measured for all individuals before and after challenge with modified live CSF (classical swine fever) vaccine. Based on the combined data of individuals from three breed populations, genome-wide scanning of QTL for these traits was performed based on a variance component model, and the genome wide significance level for declaring QTL was determined via permutation tests as well as FDR (false discovery rate) correction. A total of 27 QTL (two for CD4+CD8+, one for CD4 +CD8-, three for CD4-CD8+, two for CD4-CD8-, nine for CD4+, two for CD8+, and eight for CD4+:CD8+ ratio) were identified with significance level of $F D R<0.10$, of which 11 were significant at the level of $F D R<0.05$, including the five significant at $F D R<0.01$.
\end{abstract}

Conclusions: Within these QTL regions, a number of known genes having potential relationships with the studied traits may serve as candidate genes for these traits. Our findings herein are helpful for identification of the causal genes underlying these immune-related trait and selection for immune capacity of individuals in swine breeding in the future.

Keywords: T lymphocyte subpopulations, quantitative trait loci, swine

\section{Background}

Infectious diseases cause many serious economic and welfare problems in current swine industry and some of them belong to zoonoses, leading to potential risks to human health. Currently the main way of dealing with infectious diseases in swine is to prevent infection through hygienic measures, vaccination and supplementation of antibiotic in feed. However, these measures could not solve this problem completely [1,2]. Alternatively, breeding for enhanced immune capacity and improved resistance to infectious diseases provides a promising way to address

\footnotetext{
* Correspondence: qzhang@cau.edu.cn

+ Contributed equally

${ }^{1}$ Key Laboratory of Animal Genetics Breeding and Reproduction, Ministry of Agriculture, College of Animal Science and Technology, China Agricultural University, Beijing 100193, China

Full list of author information is available at the end of the article
}

potential disease issues from a genetic perspective. Moreover, swine are increasingly used as a large animal model for several human diseases [3-6]. Therefore, the functions of porcine immune system become more and more interesting both in basic and applied research.

The immune system plays an essential role in disease resistance of animals. Lymphocytes, also called white blood cells, have been wildly recognized as a major component of the adaptive immune system, assuming very crucial responsibility for immunity as well as allergy. Lymphocytes are basically divided into two categories, namely $\mathrm{T}$ and $\mathrm{B}$ lymphocytes, each responsible for a particular branch of the immune system. T-lymphocytes are mostly responsible for fighting microbes, antigens or foreign substances inside the cells, triggering so-called cell-mediated immunity.

\section{Biomed Central}


CD4+ and CD8+ T cells are two important subsets of $\mathrm{T}$ lymphocytes, which are highly relevant to immune capacity. In detail, CD4 is the official designation for T-cell surface antigen T4/leu3. The functions of CD4 are to initiate or augment the early phase of $\mathrm{T}$-cell activation. CD4 binds to relatively invariant sites on class II major histocompatibility complex (MHC) molecules outside the peptide-binding groove, which interacts with the $\mathrm{T}$-cell receptor (TCR) $[7,8]$. Through its portion that resides inside the $\mathrm{T}$ cell, $\mathrm{CD} 4$ amplifies the signal raised from TCR by recruiting the lymphocyte-specific protein tyrosine kinase (LCK), which is essential for activating many molecules involved in the signaling cascade of an activated T cell. Buttini et al. [9] concluded that human CD4 may function as an important mediator of indirect neuronal damage in infectious and immune-mediated diseases of the central nervous system. The expression of human CD4 in microglia/macrophages creates a pathogenetic link between the immune system and the central nervous system. Based on their immunohistochemical features, CD4+ T cells are responsible for activating and directing other immune cells. They are essential in determining B cell antibody class switching, activating cytotoxic $\mathrm{T}$ cells, and maximizing bactericidal activity of phagocytes such as macrophages. Shedlock and Shen [10] also showed that CD4+ $\mathrm{T}$ cells are required in the priming phase for functional CD8 memory.

CD8 antigen is a cell surface glycoprotein found in most cytotoxic $\mathrm{T}$ lymphocytes that mediates efficient cell-cell interactions within the immune system. CD8 antigen, acting as a co-receptor, together with other TCRs on T lymphocytes, recognizes antigen processed by antigen presenting cells (APCs) in the context of class I MHC molecules [11]. The affinity between CD8 and the MHC molecule keeps the CD8+ T cells and the target cell bound tightly during antigen-specific activation. CD8+ $\mathrm{T}$ cells are capable of inducing the death of infected somatic or tumor cells; they kill cells which are infected with viruses (or other pathogens), or are otherwise damaged or dysfunctional.

In addition to the individual functions of CD4 and CD8, different combinations of them, i.e., CD4+CD8+, CD4 +CD8-, CD4-CD8+ and CD4-CD8-, as well as the ratio of $\mathrm{CD} 4+$ to $\mathrm{CD} 8+$ also vary with health and disease status, and thus are highly relevant to immune capability of individuals. Specifically, CD4-CD8+ is MHC class I restricted and mainly recognizes replicating viral antigens, while $\mathrm{CD} 4+\mathrm{CD} 8$ - is $\mathrm{MHC}$ class II restricted and responds to nonreplicating protein antigens processed by APCs [12-15]. The ratio of CD4+:CD8+ has been shown to be indicative of the general state of immune functioning, e.g., a high CD4+:CD8+ ratio may be indicative of improved immune activity $[16,17]$. In adult rats, differences in CD4:
CD8 $\mathrm{T}$ cell ratios are MHC haplotype-dependent [18]. In human, Salazar et al. [19] reported that the CD4:CD8 ratio was a useful parameter in predicting HIV-TB coinfection. In swine, a specific feature is that a substantial number of both CD4-CD8- and CD4+CD8+ T cells were found in peripheral blood [15,20-24]. Summerfield et al. [25] demonstrated that CD4+CD8+ cells in swine can function as memory $\mathrm{T}$-helper cells which proliferate upon stimulation with recall antigen.

QTL mapping has become a main tool for unraveling genetic mechanism of complex traits in livestock. Since the first study on QTL mapping in swine [26], more than 5,738 QTL have been identified for more than 558 traits http://www.animalgenome.org/QTLdb/pig.html. However, most of these QTL are relevant to production traits, and merely a small part of them [27-34] are relevant to immune-related traits. Although T lymphocyte subpopulations in peripheral blood have been recognized as a category of important immune traits, little attention has been paid to genetic basis of them, and solely a single study [27] was involved in QTL mapping for T lymphocyte subpopulations in peripheral blood in swine so far. Motivated by identifying the genetic control on T lymphocyte subpopulations and further assisting in selection for immune capacity in swine breeding, we performed herein a genomewide scan for potential QTL influencing T lymphocyte subpopulations in peripheral blood in an experimental population involving three swine breeds.

\section{Results}

Alterations of proportions of T lymphocyte subpopulations in peripheral blood after challenge

The means and standard deviations of the proportions of $\mathrm{T}$ lymphocyte subpopulations or their ratios in peripheral blood on day 20 (the day before vaccinating) and day 35 (the day two weeks after vaccinating) are shown in Table 1. Compared with the measurements on day 20, the proportions of CD4+CD8-, CD4+ and the ratio of CD4+: CD8+ T cells in blood on day 35 reduced significantly, and the proportions of CD4-CD8+, CD4+CD8+ and $\mathrm{CD} 8+\mathrm{T}$ cells in blood on day 35 increased significantly, but the proportion of CD4-CD8- T cells on day 35 changed only slightly and tended to retain after challenge.

\section{QTL affecting T lymphocyte subpopulations in peripheral blood}

The results of QTL analyses are compiled in Table 2. The distribution of identified QTL across the whole genome is also illustrated in Figure 1. A total of 27 QTL, including nine for proportion of CD4+ T cells, one for proportion of CD4+CD8- T cells, two for proportion of CD4+CD8+ T cells, two for proportion of CD4-CD8- T cells, three for proportion of CD4-CD8+ $\mathrm{T}$ cells, two for proportion of CD8+ T cells, and eight 
Table 1 Means and standard deviations of the subpopulations of peripheral blood lymphocyte traits measured before (20-day-age) and 14 days after (35-day-age) challenge with live CSF (classical swine fever) vaccine

\begin{tabular}{cccc}
\hline Trait & 20-day-age & 35-day-age & P-value $^{\text {a }}$ \\
\hline Proportion of CD4+CD8+ T cells (\%) & $8.44 \pm 3.94$ & $10.62 \pm 5.18$ & $<0.0001$ \\
Proportion of CD4+CD8- T cells (\%) & $19.12 \pm 8.05$ & $13.04 \pm 7.71$ & $<0.0001$ \\
Proportion of CD4-CD8+ T cells (\%) & $37.27 \pm 14.65$ & $40.80 \pm 12.10$ & 0.0009 \\
Proportion of CD4-CD8- T cells (\%) & $36.96 \pm 34.03$ & $34.85 \pm 12.12$ & 0.2960 \\
Proportion of CD4+ T cells (\%) & $27.51 \pm 9.05$ & $24.53 \pm 9.13$ & $<0.0001$ \\
Proportion of CD8+ T cells (\%) & $45.74 \pm 15.14$ & $51.37 \pm 13.35$ & $<0.0001$ \\
Ratio of CD4+:CD8+ T cells & $0.70 \pm 0.39$ & $0.52 \pm 0.29$ & $<0.0001$ \\
\hline
\end{tabular}

${ }^{a}$ : Derived from t-test for comparing the differences between two ages.

for ratio of CD4+: CD8+ T cells, were identified at the significance level of with FDR $=0.1$. Some QTL on Sus Scrofa (SSC) Chromosomes 1, 4, 6, 8, 13 and 16 influenced more than one trait. On SSC8, four QTL for proportions of CD8+, CD4-CD8+, CD4+, and ratio of CD4+:CD8+ T cells, respectively, are located around marker KS139. On SSC13, the SW344-SW1008 region was found to harbor QTL for the proportions of CD4CD8-, CD4-CD8+, CD8+ and ratio of CD4+:CD8+ $\mathrm{T}$ cells.

Table 2 Results of QTL mapping for the subpopulations of peripheral blood lymphocyte traits

\begin{tabular}{|c|c|c|c|c|c|c|c|}
\hline \multirow[t]{2}{*}{ Chromosome } & \multirow[t]{2}{*}{ Position $^{\mathrm{a}}$ (cM) } & \multirow[t]{2}{*}{ Trait } & \multirow[t]{2}{*}{ LR-value $^{\mathrm{b}}$} & \multirow[t]{2}{*}{ P-value ${ }^{c}$} & \multirow[t]{2}{*}{ FDR level $^{d}$} & \multirow{2}{*}{$\begin{array}{c}\text { Flanking } \\
\text { Left }\end{array}$} & \multirow{2}{*}{$\begin{array}{c}\text { markers } \\
\text { Right }\end{array}$} \\
\hline & & & & & & & \\
\hline & 24 & CD4+ & 8.12 & 0.014 & $\$$ & SW64 & SWR2300 \\
\hline \multirow[t]{2}{*}{ SSC1 } & 24 & $\mathrm{CD} 4+$ & 8.12 & 0.014 & $\$$ & SW64 & SWR2300 \\
\hline & & $\mathrm{CD} 4+/ \mathrm{CD} 8+$ & 13.46 & 0.001 & $* *$ & SW64 & SWR2300 \\
\hline \multirow[t]{3}{*}{ SSC4 } & 73 & $\mathrm{CD} 4+/ \mathrm{CD} 8+$ & 21.67 & $<0.001$ & $* *$ & S0023 & SW512 \\
\hline & 100 & CD4+CD8- & 24.34 & 0.005 & $*$ & SW524 & SW2435 \\
\hline & & CD4+ & 30.18 & $<0.001$ & $* *$ & SW524 & SW2435 \\
\hline \multirow[t]{2}{*}{ SSC5 } & 1 & $\mathrm{CD} 4+/ \mathrm{CD} 8+$ & 10.5 & 0.006 & $\$$ & SW413 & SW491 \\
\hline & 24 & CD4+ & 8.62 & 0.009 & $\$$ & SW491 & SWR453 \\
\hline \multirow[t]{2}{*}{ SSC6 } & 76 & CD4+ & 13.44 & 0.002 & * & SW1067 & SW1129 \\
\hline & & $\mathrm{CD} 4+/ \mathrm{CD} 8+$ & 10.08 & 0.008 & $\$$ & SW1067 & SW1129 \\
\hline SSC7 & 124 & $\mathrm{CD} 4+/ \mathrm{CD} 8+$ & 11.24 & 0.004 & * & SW581 & S0101 \\
\hline \multirow[t]{4}{*}{$\mathrm{SSC} 8$} & 65 & CD4+ & 10.99 & 0.004 & * & SE47610 & KS139 \\
\hline & & $\mathrm{CD} 4+/ \mathrm{CD} 8+$ & 9.82 & 0.001 & $* *$ & SE47610 & KS139 \\
\hline & 66 & CD4-CD8+ & 7.46 & 0.02 & $\$$ & KS139 & S0225 \\
\hline & & CD8+ & 10.37 & 0.003 & * & KS139 & S0225 \\
\hline SSC9 & 99 & $\mathrm{CD} 4+$ & 6.93 & 0.018 & $\$$ & SW989 & SW2093 \\
\hline SSC11 & 73 & CD4+ & 13.13 & 0.002 & * & SW1377 & SW1494 \\
\hline \multirow[t]{4}{*}{$\mathrm{SSC} 13$} & 30 & CD4-CD8+ & 11.59 & 0.002 & * & SW344 & SWR1008 \\
\hline & & CD4-CD8- & 9.63 & 0.007 & $\$$ & SW344 & SWR1008 \\
\hline & & CD8+ & 10.05 & 0.008 & $\$$ & SW344 & SWR1008 \\
\hline & & $\mathrm{CD} 4+/ \mathrm{CD} 8+$ & 7.6 & 0.016 & $\$$ & SW344 & SWR1008 \\
\hline SSC14 & 6 & CD4-CD8+ & 7.79 & 0.02 & $\$$ & SW857 & S0089 \\
\hline SSC15 & 57.5 & $\mathrm{CD} 4+/ \mathrm{CD} 8+$ & 14.7 & 0.001 & $* *$ & S0118 & SW1683 \\
\hline \multirow[t]{2}{*}{ SSC16 } & 16 & $\mathrm{CD} 4+\mathrm{CD} 8+$ & 9.83 & 0.007 & $\$$ & SW742 & SW2411 \\
\hline & 17 & CD4+ & 9.07 & 0.015 & $\$$ & SW2411 & KS601 \\
\hline SSC17 & 95 & $\mathrm{CD} 4+\mathrm{CD} 8+$ & 8.41 & 0.014 & $\$$ & S0359 & SW2427 \\
\hline \multirow[t]{2}{*}{$\operatorname{ssc} X$} & 84 & CD4+ & 8.67 & 0.005 & $\$$ & SE15078 & SW1943 \\
\hline & 104.8 & CD4-CD8- & 9.35 & 0.007 & $\$$ & S0511 & SW2137 \\
\hline
\end{tabular}

\footnotetext{
${ }^{a}$ : Position corresponding to the peak of the LR profile.

${ }^{b}$ : LR value at the peak of the LR profile.

c: Derived from the empirical distribution obtained via 1,000 permutations.

${ }^{\mathrm{d}}$ : \$, FDR $<0.10 ;{ }^{*}, \mathrm{FDR}<0.05 ;{ }^{*}, \mathrm{FDR}<0.01$.
} 


\section{Discussion}

Direct selection based upon observation of resistance and susceptibility to individual infections and diseases is generally infeasible [35]. The reason lies in two aspects: On the one hand, if the observation is made under normal production conditions, the phenotypes would not be very informative, because it is questionable to observe disease status of individuals with low disease resistance ability under good hygiene and management environment. On the other hand, if the observation is made under challenging conditions, it would be costly and productivity could be adversely influenced. $\mathrm{T}$ cells are the major cell populations mediating the adaptive arm of the immune system. Several studies on T cell subpopulations showed that variations in CD4 and CD8 $\mathrm{T}$ cell levels and CD4:CD8 ratio are significantly 
heritable [36-38]. Heritability estimates were around $65 \%$ for CD4:CD8 ratio, $50 \%$ for CD4+ counts, and $56 \%$ for CD8+ counts [38]. Ahmadi et al. [39] reported that heritability estimates are $54 \%$ for CD $4+$ counts, and 56\%-62\% for CD8+ counts. Therefore, as a category of immune-related traits with high heritabilities, $\mathrm{T}$ lymphocyte subpopulations can be possibly implemented to select for disease resistance and susceptibility in swine breeding. The present results clearly show that a number of loci contribute to the variation of $\mathrm{T}$ lymphocyte subpopulations in peripheral blood in pig. These findings would enhance our understanding of genetic control of the variations of $\mathrm{T}$ lymphocyte subpopulations.

In swine, very limited results on QTL mapping for $T$ lymphocyte subpopulations in peripheral blood were reported so far. In the study of Wattrang et al. [27], a QTL for number of CD8+ cells and a QTL for number of CD2+ cells in a European Wild boar $\times$ Swedish Yorkshire inter-cross population were detected on SSC1. Within these QTL regions, no QTL was identified in our study, rather, two novel QTL, one for proportion of CD4+ T cells and the other for CD4:CD8 ratio, were mapped between SW64-SWR2300 on SSC1. This may be due to the difference of animal resources utilized in the two studies.

Compared with previous results of QTL mapping for immune related traits in swine, some QTL regions identified in this study are overlapping with those for other immune traits. Specifically, we identified two QTL for ratio of $\mathrm{CD} 4+: \mathrm{CD} 8+$ on SSC4 and SSC6, respectively. In the same chromosomal regions, two QTL for PWMinduced leukocytes proliferation were identified by Edfors-Lilja et al. [29]. Similarly, Reiner et al. [33] found a QTL on SSC13 for share of neutrophils and a QTL on SSC16 for share of basophils in pigs after challenge with Sarcocystis miescheriana. Overlapping with these two regions, four QTL with effects on proportions of CD4CD8-, CD4-CD8+, CD8+ and CD4:CD8 ratio on SSC13, and two QTL on SSC16 for proportions of CD4+CD8+ and $\mathrm{CD} 4+\mathrm{T}$ cells were determined in our study. These findings indicated that some immune-related traits in swine may be controlled by genes in tight linkage or same genes with pleiotropic effects. In addition, in our recent studies [28,34], a total of 46 QTL for two types of immune-related traits have been detected based on the same experimental population as in current study, including 11 QTL for three cytokine traits and 35 QTL for 18 haematological traits. These QTL are located across the whole genome except SSC18. Comparison of these QTL regions with those revealed in this study demonstrates that some of QTL underlying different immune-related traits trend to cluster within the same chromosomal regions. For example, QTL affecting level of IL-10, mean corpuscular hemoglobin $(\mathrm{MCH})$, mean corpuscular hemoglobin concentration $(\mathrm{MCHC})$ and red blood cell volume distribution width (RDW) were mapped within the interval of SW174-SW1651 on SSC9; Within two conjunct intervals of SW742-SW2411 and SW2411-KS601, QTL controlling MCHC, ratio of IFN- $\gamma$ : IL-10 and proportions of CD4+CD8+, CD4+ were identified. This may suggest a common underlying mechanism predisposing the variation of certain immune-related traits.

In our earlier study [40], differences on $\mathrm{T}$ lymphocyte subpopulations among the three swine breeds have been investigated based on the same experimental animals, and the percentages of three types of $\mathrm{T}$ lymphocyte subpopulations, including $\mathrm{CD} 4+\mathrm{CD} 8+, \mathrm{CD} 4+\mathrm{CD} 8-$, and CD4-CD8-, were detected to be significantly different among the three pig breeds. This is the reason why we considered breed as a fixed factor in the statistical model to avoid potential confounding between effects of QTL and breed in present study. Hence, the statistical model adopted herein can suit well for the experimental design in this study because: 1 ) several previous studies [41-43] have demonstrated the advantages of a joint analysis across multiple populations with different genetic background over a single population analysis in QTL mapping; 2) all the animals of the three breeds involved in our study were reared on the same farm under the same conditions, ensuring no confounding or interaction between breed and environmental effects; and 3) the sample size of each breed is relatively small, and thus individual analyses within each breed are not feasible to obtain convincing results.

Some QTL reported in this study were mapped in the regions harboring several known genes, which have been reported in human or mice to have direct or indirect relationship with the traits considered in this research. Specifically, the QTL region on SSC1 for CD4: CD8 ratio harbors two genes, TNFAIP3 (tumor necrosis factor, alpha-induced protein 3) and IFNGR1 (interferon gamma receptor 1). TNFAIP3 in dendritic cells plays crucial role in controlling the magnitude of CD8+ and $\mathrm{CD} 4+\mathrm{T}$ cell responses during both the priming and effector phases of immune response [44]. Tewari et al. [45] reported that the IFN-gamma receptor deficiency altered the epitope hierarchy of the pool of lymphocytic choriomeningitis virus-specific memory CD8 T cells in an acute infection. Another CD4:CD8 ratio QTL region on SSC4 harbors three genes, i.e., IL6R (interleukin 6 receptor), CD1D (CD1d molecule), and TOX (thymocyte selection-associated high mobility group box). IL6R is expressed on resting CD4+ and CD8+ cells, and its expression can significantly be enhanced on both activated CD4+ and CD8+ cells [46]. Thedrez et al. [47] showed that CD4 potentiates human iNKT cell activation by engaging CD1d molecules. Wilinson et al. [48] 
reported that transgenic mice that express TOX show expanded $\mathrm{CD} 8+$ and reduced $\mathrm{CD} 4+$ single positive thymocyte subpopulations. Two QTL for proportion of CD4+ and CD4:CD8 ratio, respectively, are located in the same region on SSC6. The IL29 (interleukin 29) gene is located in this region, which is an inhibitor of Th2 cytokine responses [49]. There are two genes, IL2 (interleukin 2) and IL21 (interleukin 21), which are located close to the QTL for proportion of CD4-CD8+ on SSC8. IL2 acts as a growth hormone for both B and $\mathrm{T}$ lymphocytes [50]. IL21 plays a global role in regulating T cell homeostasis [51]. On SSC15, a QTL for CD4: CD8 ratio was mapped to the region proximal to the TLR3 (toll-like receptor 3) gene. Salem et al. [52] suggested that $\mathrm{CD} 8+\mathrm{T}$ cells can be activated by triggering their TLR3. The ADA (adenosine deaminase) gene is located close to the QTL for proportion of CD4+CD8+ on SSC17. Apasov et al. [53] found that the Ada -/mice had a pronounced decrease in the size and lymphocyte content compared to the wild type mice.

It is well known that swine genome shows high homology to that of human and mice. From the viewpoint of comparative genomics, the same gene likely shows the similar function in swine, human and mice, which suggests that the genes aforementioned may serve as candidate genes for the traits of $\mathrm{T}$ lymphocyte subpopulations in swine. It is notable that QTL mapping performed in this study is the first step toward identification of the actual functional genes. Further endeavors focusing on the association between these genes and $\mathrm{T}$ lymphocyte traits will be pursued in our follow-up study.

\section{Conclusions}

In swine, very few papers about QTL for T lymphocyte subpopulations in peripheral blood were available. In this study, 27 QTL with significance level of $F D R<0.10$ were identified for 7 traits: two for $\mathrm{CD} 4+\mathrm{CD} 8+$, one for CD4+CD8-, three for CD4-CD8+, two for CD4-CD8-, nine for $\mathrm{CD} 4+$, two for $\mathrm{CD} 8+$, and eight for $\mathrm{CD} 4+$ :CD8+ ratio. Within these QTL regions, a number of known genes were further revealed. Our results should be helpful for identifying the causal genes underlying these trait variations in swine.

\section{Methods}

The animals and collection of blood samples

The animals consisted of 367 piglets distributed in 5 Landrace boar families (15 sows and 87 piglets), 7 Large White boar families (33 sows and 190 piglets), and 4 Songliao Black Pig boar families (15 sows and 90 piglets), respectively. All pigs were raised under standard indoor conditions at the experimental farm of the Institute of Animal Sciences, Chinese Academy of Agricultural Sciences, Beijing, China.
All piglets were vaccinated with live CSF vaccine at 21 days of age. Blood samples were collected from each piglet one day before the vaccination inoculation (day 20 ) and two weeks after the vaccination (day 35), respectively. The samples were directly injected into eppendorf tubes containing $60 \mu \mathrm{l}$ of $20 \%$ EDTA in phosphate-buffered saline (PBS).

\section{Identification of T lymphocyte subpopulations in peripheral blood}

$\mathrm{CD} 4+$ and $\mathrm{CD} 8+\mathrm{T}$ lymphocytes were obtained by the double cytofluorometric analysis. The blood cells were incubated with $10 \mu \mathrm{l}$ of mouse anti porcine CD4-FITC (Serotec UK) and $10 \mu \mathrm{l}$ of mouse anti porcine CD8-RPE (Serotec, UK) for $30 \mathrm{~min}$, and then washed with $0.1 \mathrm{M}$ PBS (pH 7.2, containing $0.3 \%$ bovine serum albumin). The red blood cells were digested with $0.1 \%$ ammonium oxalate solution. The stained cells were analyzed by cytofluorometry (Epicselite, Beckman-Coulter, USA) to determine the CD4/CD8-defined T lymphocyte subpopulations: proportions of CD4+, CD8+, CD4+CD8+, CD4+CD8-, CD4-CD8+ and CD4-CD8-, and ratio of $\mathrm{CD} 4+: \mathrm{CD} 8+$.

\section{Genetic markers}

206 microsatellites were selected from NCBI http:// www.ncbi.nlm.nih.gov/ and the latest porcine sex-average linkage map in NCBI was used in QTL mapping. These markers are approximately evenly distributed throughout the 18 autosomes and the $\times$ chromosome. The average distance between adjacent microsatellites on the sex-averaged map was $12 \mathrm{cM}$. The number of markers and their mean polymorphic information content (PIC) [54] on each chromosome are shown in Table 3.

\section{Statistical analysis}

Interval mapping of QTL was performed using the variance component approach [55-57] based on a linear mixed model as follows,

$$
\begin{aligned}
& \mathbf{y}=\mathbf{X} \mathbf{a}+b \mathbf{c}+\mathbf{Z u}+\mathbf{T} \mathbf{v}+\mathbf{e} \\
& \mathbf{u} \sim \mathrm{N}\left(\mathbf{0}, \mathbf{A} \sigma_{u}^{2}\right), \mathbf{v} \sim \mathrm{N}\left(\mathbf{0}, \mathbf{Q} \sigma_{v}^{2}\right), \mathbf{e} \sim \mathrm{N}\left(\mathbf{0}, \mathbf{I} \sigma_{e}^{2}\right), \operatorname{Cov}\left(\mathbf{u}, \mathbf{v}^{\prime}\right)=\mathbf{0}
\end{aligned}
$$

where $\mathbf{y}$ is a vector of the phenotypic values for the proportions of peripheral blood lymphocyte or their ratios measured on day 35 , a is a vector of fixed effects including breed, sex and sampling batch, $\mathbf{c}$ is a vector of the proportions of peripheral blood lymphocyte or their ratios measured on day $20, b$ is the regression coefficient, $\mathbf{u}$ is a vector of residual polygenic effects, $\mathbf{v}$ is a vector of QTL allelic effects, $\mathbf{e}$ is a vector of residuals, $\mathbf{X}, \mathbf{Z}$, and $\mathbf{T}$ are incidence matrices for $\mathbf{a}, \mathbf{u}$, and $\mathbf{v}$, 
Table 3 Number of markers and their mean polymorphic information content (PIC) ${ }^{a}$ on each chromosome

\begin{tabular}{cccccccccccccccccccc}
\hline Chr. & $\mathbf{1}$ & $\mathbf{2}$ & $\mathbf{3}$ & $\mathbf{4}$ & $\mathbf{5}$ & $\mathbf{6}$ & $\mathbf{7}$ & $\mathbf{8}$ & $\mathbf{9}$ & $\mathbf{1 0}$ & $\mathbf{1 1}$ & $\mathbf{1 2}$ & $\mathbf{1 3}$ & $\mathbf{1 4}$ & $\mathbf{1 5}$ & $\mathbf{1 6}$ & $\mathbf{1 7}$ & $\mathbf{1 8}$ & $\mathbf{X}$ \\
\hline Number of markers & 13 & 9 & 14 & 13 & 12 & 12 & 14 & 12 & 12 & 12 & 7 & 11 & 12 & 11 & 9 & 8 & 8 & 4 & 13 \\
Mean PIC & 0.63 & 0.68 & 0.61 & 0.54 & 0.49 & 0.65 & 0.63 & 0.57 & 0.51 & 0.53 & 0.58 & 0.47 & 0.55 & 0.62 & 0.56 & 0.55 & 0.55 & 0.45 & 0.51 \\
\hline
\end{tabular}

a: The PIC for each marker was calculated as PIC $=1-\sum_{i=1}^{n} P_{i}^{2}-\sum_{i=1}^{n-1} \sum_{j=i+1}^{n} 2 P_{i}^{2} P_{j}^{2}$

where $P_{i}$ is the frequency of the ith allele, $P_{j}$ is the frequency of the jth allele and $\mathrm{n}$ is the number of animals in the population.

respectively, $\mathbf{A}$ is the additive genetic relationship matrix among all individuals, $\sigma_{u}^{2}$ is the additive polygenetic variance, $\mathbf{Q}$ is the IBD probability matrix among $\mathrm{QTL}$ alleles which was constructed based on multi-locus marker genotypes using the Monte-Carlo approximation method proposed by Grignola et al.[57], $\sigma_{v}^{2}$ is the QTL allelic variance, $\mathbf{I}$ is an unit matrix, and $\sigma_{e}^{2}$ is the residual variance.

The QTL analysis was scanned along each chromosome at every interval of $1 \mathrm{cM}$. Restricted maximum likelihood (REML) was used to estimate the three variance components in the model and the likelihood ratio (LR) was calculated as test statistic for each particular location on the chromosome as follows

$$
L R=-2 \ln \frac{L_{\mathrm{MAX}} \mid \mathrm{H}_{0}}{L_{\mathrm{MAX}} \mid \mathrm{H}_{\mathrm{A}}}
$$

where $L_{\mathrm{MAX}} \mid \mathrm{H}_{0}$ and $L_{\mathrm{MAX}} \mid \mathrm{H}_{\mathrm{A}}$ are restricted maximum likelihood functions corresponding to the null hypothesis (there is no QTL) and the alternative hypothesis (there is a QTL), respectively.

The program MQREML developed by Zhang and Hoeschele [56] was used for the calculation mentioned above.

When the distribution of the phenotypes is normal or nearly normal, it is generally regarded that the LR statistic follows approximately a $\chi^{2}$ distribution with degrees of freedom between one and two. However, the distributions of the traits measured in this study are severe departing from normal, and a data transformation using Box-Cox approach does not help much. So, we adopted the permutation approach [58] to obtain the empirical distribution of the LR statistic. For each chromosome and each trait, 1,000 permutations of the phenotypes were performed and from the empirical distributions of the LR-values the probability corresponding to the observed LR value was obtained. In order to avoid the increase of false positive rate caused by multiple tests, the FDR (false discovery rate) control approach [59] was adopted to determine the significance levels for declaring significant QTL. Compared with the traditional method of controlling family wise error rate (FWER), such as Bonferroni correction, the FDR method is less conservative, leading to an essential gain in power. Thus FDR is increasingly being adopted in area of QTL mapping experiments.

Let $m$ be the total number of tests involved in the analysis and $P_{1} \leq P_{2} \leq \cdots \leq P_{\mathrm{m}}$ be the ordered observed $P$-values corresponding to the empirical distributions for the $m$ tests, the $F D R$ for $P_{i}(i=1,2, \ldots, m)$ is calculated as

$$
F D R=\frac{m P_{i}}{i}
$$

In this study, there were 7 phenotypic traits and 19 chromosomes, leading to the total number of tests $m=$ $7 \times 19=133$.

\section{Acknowledgements and Funding}

We would like to thank the editor and the three peer reviewers for their constructive comments and suggestions which greatly improve our manuscript. We also give thanks to all members in our lab for their excellent technical supports. This study was supported by the National Natural Science Foundations of China (30972092), the Natural Science Foundations of Beijing (6102016), New-Century Training Programme Foundation for the Talents by the State Education Commission of China (NETC-10-0783), Scientific Research Foundation for the Returned Overseas Chinese Scholars of State Education Ministry, and the National High Technology Research and Development Program of China (863 Program 2011AA100302).

\section{Author details}

${ }^{1}$ Key Laboratory of Animal Genetics Breeding and Reproduction, Ministry of Agriculture, College of Animal Science and Technology, China Agricultural University, Beijing 100193, China. ${ }^{2}$ State Key Laboratory for Infectious Disease Prevention and Control, National Institute for Communicable Disease Control and Prevention, Chinese Center for Disease Control and Prevention, P.O. Box 5, Changping, Beijing 102206, China. ${ }^{3}$ Department of Animal Science, Hebei Normal University of Science and Technology, Changli, Hebei 066600, China.

\section{Authors' contributions}

$\mathrm{XL}$ and JFL are the major executive persons of all jobs of this research and drafted this manuscript together. YFG assisted in the collection of the phenotypes and marker genotyping. ZPW assisted in the statistical analysis. $\mathrm{YL}$ assisted in phenotype collecting. QZ planed and supervised the whole study. All authors read and approved the final manuscript.

\section{Competing interests}

The authors declare that they have no competing interests.

Received: 31 March 2011 Accepted: 16 September 2011 Published: 16 September 2011 


\section{References}

1. Wiseman J, Varley MA, Chadwick JP: Progress in Pig Science. Nottingham: Nottingham University Press; 1998, 29-38.

2. Visscher AH, Janss LLG, Niewold TA, De Greef KH: Disease incidence and immunological traits for the selection of healthy pigs. Vet Q 2002, 24:29-34.

3. Sinkora M, Butler JE, Holtmeier W, Sinkorova J: Lymphocyte development in fetal piglets: facts and surprises. Vet Immunol Immunopathol 2005, 108(1-2):177-184.

4. Alving K: Airways vasodilatation in the immediate allergic reaction. Involvement of inflammatory mediators and sensory nerves. Acta Physiol Scand Supp/ 1991, 597:1-64

5. Kenmochi T, Mullen Y, Miyamoto M, Stein E: Swine as an allotransplantation model. Veterinary Immunology and Immunopathology 1994, 43(1-3):177-1831.

6. Misfeldt ML, Grimm DR: Sinclair miniature swine: an animal model of human melanoma. Vet Immunol Immunopathol 1994, 43:161.

7. Reinherz EL, Schlossman SF: The differentiation and function of human $T$ lymphocytes. Cell 1980, 19(4):821-827.

8. Doyle C, Strominger JL: Interaction between CD4 and class II MHC molecules mediates cell adhesion. Nature 1987, 330(6145):256-259.

9. Buttini M, Westland CE, Masliah E, Yafeh AM, Wyss-Coray T, Mucke L: Novel role of human CD4 molecule identified in neurodegeneration. Nature Med 1998, 4:441-446.

10. Shedlock DJ, Shen H: Requirement for CD4 T cell help in generating functional CD8 T cell memory. Science 2003, 300:337-339.

11. Swain SL, Dutton RW, Schwab R, Yamamoto J: Xenogeneic human antimouse $T$ cell responses are due to the activity of the same functional $T$ cell subsets responsible for allospecific and major histocompatibilityrestricted responses. The Journal of Experimental Medicine 1983, 157:720

12. Weiss A: T lymphocyte activation. Fundamental immunology 1997, 467-504.

13. Unanue ER: Macrophages, antigen-presenting cells, and the phenomena of antigen handling and presentation. Fundamental immunology 1993, 111-144.

14. Doherty PC, Topham DJ, Tripp RA: Establishment and persistance of virusspecific CD4+and CD8+T cell memory. Immunol Rev 1996, 150:23-44

15. Ober BT, Summerfield A, Mattlinger C, Wiesmuller KH, Jung G, Pfaff E, Saalmuller A, Rziha HJ: Vaccine-induced, pseudorabies virus-specific, extrathymic CD4+CD8+ memory T-helper cells in swine. J Virol 1998, 72(6):4866-4873

16. Yang $X G$, Zhang $X Y$, Wang $X$ : Effect of Chinese herbal medicine mixture on immune function in chickens. J Northeast Agric Univ 2005, 36:60-65.

17. Hu YJ, Lin YC, Zhou GL, Yu DQ: Effect of Chinese extracts on performance and T lymphocyte cell subset of yellow broilers. China Poult 2003, 12:14-17.

18. Damoiseaux JG, Cautain B, Bernard I, Mas M, Van Breda Vriesman PJ, Druet $P$, Fournie $G$, Saoudi A: A dominant role for the thymus and $M H C$ genes in determining the peripheral CD4/CD8 T cell ratio in the rat. $J$ Immunology 1999, 163:2983.

19. Salazar RA, Souza VL, Khan AS, Fleischman JK: Role of CD4:CD8 ratio in predicting HIV co-infection in patients with newly diagnosed tuberculosis. AIDS Patient Care STDS 2000, 14(2):79-83.

20. Binns RM, Duncan IA, Powis SJ, Hutchings A, Butcher G: Subsets of null and gamma delta T-cell receptor $1 \mathrm{~T}$ lymphocytes in the blood of young pigs identified by specific monoclonal antibodies. Immunology 1992, 177:219-227

21. Carr MM, Howard CJ, Sopp P, Manser JM, Parsons KR: Expression of porcine $\mathrm{g} / \mathrm{d}$ T lymphocytes of a phylogenetically conserved surface antigen previously restricted in expression of ruminant $\mathrm{gd} T$ lymphocytes. Immunology 1994, 81:36-40.

22. Hirt W, Saalmüller A, Reddehase JM: Distinct $\mathrm{g} / \mathrm{d}$ T cell receptors define two subsets of circulating porcine CD22CD42CD82 Tlymphocytes. $J$ Immunology 1990, 20:265-269.

23. Saalmüller A, Hirt W, Reddehase MJ: Porcine $\mathrm{g} / \mathrm{d}$ T lymphocyte subsets differing in their propensity to home to the lymphoid tissue. Eur $J$ Immunol 1990, 20:2343-2346.

24. Sinkora J, Rehakova Z, Sinkora M, Cukrowska B, Tlaskalova-Hogenova H: Early development of immune system in pigs. Vet Immunol Immunopathol 2002, 87(3-4):301-306.
25. Summerfield A, Rziha HJ, Saalmüller A: Functional characterization of porcine CD4+CD8+ extrathymic T lymphocytes. Cell Immunol 1996, 168:291-296.

26. Andersson L, Haley CS, Ellegren H, Knott SA, Johansson M, Andersson K, Andersson-Eklund L, Edfors-Lilja I, Fredholm M, Hansson I, et al: Genetic mapping of quantitative trait loci for growth and fatness in pigs. Science 1994, 263:1771-1774

27. Wattrang E, Almqvist M, Johansson A, Fossum C, Wallgren P, Pielberg G, Andersson L, Edfors-Lilja I: Confirmation of QTL on porcine chromosomes 1 and 8 influencing leukocyte numbers, haematological parameters and leukocyte function. Anim Genet 2005, 36(4):337-345.

28. Gong YF, Lu X, Wang ZP, Hu F, Luo YR, Cai SQ, Qi CM, Li S, Niu XY, Qiu XT, et al: Detection of quantitative trait loci affecting haematological traits in swine via genome scanning. BMC Genet 2010, 11:56.

29. Edfors-Lilja I, Wattrang E, Marklund L, Moller M, Andersson-Eklund L, Andersson L, Fossum C: Mapping quantitative trait loci for immune capacity in the pig. J Immunology 1998, 160:829-835.

30. Edfors-Lilja I, Wattrang E, Andersson L, Fossum C: Mapping quantitative trait loci for stress induced alterations in porcine leukocyte numbers and functions. Animal Genetics 2000, 31:186-193.

31. Zou Z, Ren J, Yan X, Huang X, Yang S, Zhang Z, Yang B, Li W, Huang L: Quantitative trait loci for porcine baseline erythroid traits at three growth ages in a White Duroc 3 Erhualian F2 resource population. Mamm Genome 2008.

32. Reiner G, Fischer R, Hepp S, Berge T, Köhler F, Willems H: Quantitative trait loci for red blood cell traits in swine. Animal Genetics 2007, 38:447-452

33. Reiner G, Fischer R, Hepp S, Berge T, Kohler F, Willems H: Quantitative trait loci for white blood cell numbers in swine. Anim Genet 2008, 39(2):163-168.

34. Lu X, Gong YF, Liu JF, Wang ZP, Hu F, Qiu XT, Luo YR, Zhang Q: Mapping quantitative trait loci for cytokines in the pig. Anim Genet 2011, 42(1):1-5.

35. Wilkie B, Mallard B: Selection for high immune response: an alternative approach to animal health maintenance. Vet Immunol Immunopathol 1999, 72:231-235.

36. Amadori A, Zamarchi $R$, Chieco-Bianchi L: CD4: CD8 ratio and HIV infection: the "tap-and-drain" hypothesis. Immunol Today 1996, 17:414-417.

37. Evans DM, Frazer $\mathrm{H}$, Martin NG: Genetic and environmental causes of variation in basal levels of blood cells. Twin Res 1999, 2:250-257.

38. Hall MA, Ahmadi KA, Norman P, Snieder H, Macgregor A, Vaughan RW, Spector TD, Lanchbury JS: Genetic influence on peripheral blood T lymphocyte levels. Genes Immun 2000, 1:423-427.

39. Ahmadi KR, Hall MA, Norman P, Vaughan RW, Snieder H, Spector TD, Lanchbury JS: Genetic determinism in the relationship between human CD4+ and CD8+ T lymphocyte populations? Genes Immun 2001, 2(7):381-387

40. Liu Y, Luo YR, Lu X, Qiu XT, Fu WX, Zhou JP, Liu XY, Zhang Q, Yin ZJ: Investigation and Comparative Study on Haematological Traits, Lysozyme Concentration and T Lymphocyte Subpopulation in Three Pig Breeds. Journal of Animal and Veterinary Advances 2010, 9(21):2748-2751.

41. Kim JJ, Rothschild MF, Beever J, Rodriguez-Zas S, Dekkers JC: Joint analysis of two breed cross populations in pigs to improve detection and characterization of quantitative trait loci. J Anim Sci 2005, 83(6):1229-1240.

42. Perez-Enciso M, Mercade A, Bidanel JP, Geldermann H, Cepica S, Bartenschlager H, Varona L, Milan D, Folch JM: Large-scale, multibreed, multitrait analyses of quantitative trait loci experiments: the case of porcine $\times$ chromosome. J Anim Sci 2005, 83(10):2289-2296.

43. Walling GA, Visscher PM, Andersson L, Rothschild MF, Wang L, Moser G, Groenen MA, Bidanel JP, Cepica S, Archibald AL, et al: Combined analyses of data from quantitative trait loci mapping studies. Chromosome 4 effects on porcine growth and fatness. Genetics 2000, 155(3):1369-1378.

44. Song XT, Evel-Kabler K, Shen L, Rollins L, Huang XF, Chen SY: A20 is an antigen presentation attenuator, and its inhibition overcomes regulatory T cell-mediated suppression. Nat Med 2008, 14(3):258-265.

45. Tewari K, Sacha J, Gao X, Suresh M: Effect of chronic viral infection on epitope selection, cytokine production, and surface phenotype of CD8 T cells and the role of IFN-gamma receptor in immune regulation. $J$ Immunol 2004, 172(3):1491-1500.

46. Bulgarini D, Scalzo S, Boccoli G, Petrini M, Quaranta MT, Camagna A, Isacchi G, Testa U, Peschle C: IL-6/BSF-2 selectively stimulates the GO-_ 
S progression of CD8+ lymphocytes. J Biol Regul Homeost Agents 1991, 5(1):23-33.

47. Thedrez A, de Lalla C, Allain S, Zaccagnino L, Sidobre S, Garavaglia C, Borsellino $G$, Dellabona $P$, Bonneville $M$, Scotet $E$, et al: CD4 engagement by CD1d potentiates activation of CD4+ invariant NKT cells. Blood 2007 , 110(1):251-258.

48. Wilkinson B, Chen JY, Han P, Rufner KM, Goularte OD, Kaye J: TOX: an HMG box protein implicated in the regulation of thymocyte selection. Nat Immunol 2002, 3(3):272-280.

49. Srinivas S, Dai J, Eskdale J, Gallagher GE, Megjugorac NJ, Gallagher G: Interferon-lambda1 (interleukin-29) preferentially down-regulates interleukin-13 over other T helper type 2 cytokine responses in vitro. Immunology 2008, 125(4):492-502.

50. Lowenthal JW, Zubler RH, Nabholz M, MacDonald HR: Similarities between interleukin-2 receptor number and affinity on activated $B$ and $T$ lymphocytes. Nature 1985, 315(6021):669-672.

51. Datta S, Sarvetnick NE: IL-21 limits peripheral lymphocyte numbers through T cell homeostatic mechanisms. PLoS One 2008, 3(9):e3118.

52. Salem ML, Diaz-Montero CM, El-Naggar SA, Chen Y, Moussa O, Cole DJ: The TLR3 agonist poly(l:C) targets CD8+ T cells and augments their antigenspecific responses upon their adoptive transfer into naïve recipient mice. Vaccine 2009, 27(4):549-557.

53. Apasov SG, Blackburn MR, Kellems RE, Smith PT, Sitkovsky MV: Adenosine deaminase deficiency increases thymic apoptosis and causes defective T cell receptor signaling. J Clin Invest 2001, 108(1):131-141.

54. Botstein D, White RL, Skolnick M, Davis RW: Construction of a genetic linkage map in man using restriction fragment length polymorphisms. Am J Hum Genet 1980, 32(3):314-331.

55. Liu J, Liu Y, Liu X, Deng HW: Bayesian Mapping of Quantitative Trait Loc for Multiple Complex Traits with the Use of Variance Components. The American Journal of Human Genetics 2007, 81:304-320.

56. Zhang Q, Hoeschele L: Multiple QTL mapping in outcross populations via residual maximum likelihood. Proc 6th World Congr Genet Appl Lives Prod 1998, 26:265-268.

57. Grignola FE, Hoeschele I, Tier B: Mapping quantitative trait loci in outcross populations via residual maximum likelihood. I. Methodology. Genetics Selection Evolution 1996, 28:479-490.

58. Churchill GA, Doerge RW: Empirical threshold values for quantitative trait mapping. Genetics 1994, 138(3):963-971

59. Benjamini $Y$, Hochberg $Y$ : Controlling the false discovery rate: a practical and powerful approach to multiple testing. Journal of the Royal Statistical Society 1995, 57:289-300.

doi:10.1186/1471-2156-12-79

Cite this article as: Lu et al:: Mapping quantitative trait loci for T lymphocyte subpopulations in peripheral blood in swine. BMC Genetics 2011 12:79

\section{Submit your next manuscript to BioMed Central and take full advantage of:}

- Convenient online submission

- Thorough peer review

- No space constraints or color figure charges

- Immediate publication on acceptance

- Inclusion in PubMed, CAS, Scopus and Google Scholar

- Research which is freely available for redistribution 